\title{
Skin Metatypical Carcinoma
}

National Cancer Institute

\section{Source}

National Cancer Institute. Skin Metatypical Carcinoma. NCI Thesaurus. Code C66903.

A skin carcinoma displaying cytological characteristics intermediate to nodular basal cell carcinoma and squamous cell carcinoma. 